\title{
CONSIDERAÇÕES SOBRE A RELAÇÃO ENTRE TRAUMA, PULSÃO E FANTASIA NA ESTRUTURA DA NEUROSE
}

Renato Jesus A. de Praga Palma e Ana Maria M. da Costa

Renato Jesus A. de Praga

Palma

Mestre em

Psicanálise pela

Uerj (2013),

especialista em

Psicanálise e Saúde

Mental pela mesma

Universidade

(2011), psicanalista, psicólogo clínico

da Policlínica

Militar de Niterói -

Exército Brasileiro

- e do Consultório

na Rua de Niterói

e preceptor do

Programa de

Educação pelo

Trabalho em Saúde da UFF.

Ana Maria M. da Costa

Psicanalista,

pós-doutora pela

Universidade

de Paris XIII

(2002), Recherche

Psychogenese et

Psychpathologie,

doutora em

Psicologia Clínica

pela PUC/SP

(1997), professora

adjunta do DPC/IP/

Uerj, pesquisadora

do CNPQ e membro

do Prociência.

RESUMO: Este trabalho visa articular os conceitos de trauma, pulsão e fantasia, utilizando, para esse objetivo, textos de Freud e de Lacan. Aborda-se aqui o momento primeiro em que Freud supunha que o traumatismo advinha de uma experiência factual com um terceiro, até desvendar que o conteúdo traumático seria um recobrimento fantasístico construído pelo sujeito na tentativa de se defender da força impelente da pulsão. E por ser o trauma considerado como o âmago daquilo que faz estrutura para todas as neuroses, busca-se aqui analisar as classes de neurose a partir da forma como o sujeito reponde à situação traumática.

Palavras-chave: Trauma, pulsão, fantasia, escolha da neurose, das Ding.

ABSTRACT: Considerations about the relationship between trauma, drive and fantasy in the structure of neurosis. This article aims to build a relationship between the concepts of trauma, drive and fantasy, using for this purpose, the texts of Freud and Lacan. It looks at the first time that Freud believed that the trauma came from a factual relationship with an adult, until the author discovers that the traumatic content would be a fantasmatic covering built by the subject in order to try to defend himself from the impelling force of the drive. And due to the fact that the trauma is considered the core of what makes the structure for all neurosis, we seek to examine the types of neurosis through the manner the subject responds to the traumatic situation.

Keywords: Trauma, drive, fantasy, neurosis' choice, das Ding.

DOI - http://dx.doi.org/10.1590/S1516-14982015000200003 


\section{A PERSPECTIVA ECONÔMICA DO APARELHO PSÍQUICO}

Em 1895, no Projeto para uma psicologia científica (1950[1895]/1996),Freud teceu um esclarecimento sobre a origem e o funcionamento do aparelho psíquico, tomando como base a forma de funcionamento do aparelho neurônico. Segundo ele, o ser humano seria cercado por estímulos provindos do ambiente e outros advindos do próprio corpo, como a fome, a dor, a sede, etc. E o aparato neuronal seria caracterizado não só como um sistema receptor dessas excitações internas e externas, mas também como um aparelho que teria como mecanismo descarregar qualquer aumento de excitação para mitigar o desconforto decorrente. O aumento do quantum de tensão seria causado pela incidência de algum estímulo, e proporcional à magnitude da estimulação.

Freud (idem) afirmou que esses estímulos se propagariam pelas inervações e se descarregariam através de uma atividade motora. Logo, havia um princípio de inércia que regia o aparelho neuronal, ou seja, caso algum tipo de estimulação chegasse ao sistema, este buscaria ab-reagir, visando manter-se livre do estímulo e assim retornar ao nível homeostático - em suma, buscaria evitar o desprazer e se valeria da quantidade de excitação recebida para descarregá-la através de uma atividade motora.

Para Freud (idem), a ausência ou a presença de estímulos no aparelho neurônico estavam relacionadas à ausência ou à presença de tensão no sistema e à dialética prazer-desprazer. O princípio de prazer, assim denominado pelo autor, era um dos dois princípios que regiam o funcionamento neuronal e aludia ao fato de que a dinâmica neurônica tinha por objetivo evitar o desprazer e proporcionar o prazer.

Mas, para as estimulações endógenas, deveria haver uma função secundária de funcionamento, uma vez que o organismo nem sempre podia se esquivar desses estímulos e descarregar a quantidade de excitação imediatamente. De maneira contrária, a tensão acumulada só seria mitigada caso alguma atividade fosse realizada pelo mundo externo, como, por exemplo, a alimentação fornecida por um terceiro, no caso do recém-nascido. Nessa função secundária, o sistema nervoso teria de abandonar o princípio de inércia, em que descarregaria o quantum de energia a zero, e preservar uma carga para que fosse realizada uma ação, que Freud (ibidem) chamou de específica, e, com isso, sanar a tensão proveniente da excitação. Isso pode ser exemplificado quando o bebê chora para chamar a mãe após o advento da fome, para que, com isso, obtenha o seio.

Esse modo secundário de organização, o do acúmulo de energia, instauraria a segunda lei do aparelho psíquico e formaria par com o princípio de prazer o princípio de realidade (ibidem). O sistema neurônico seguiria esse princípio quando a satisfação não pudesse ser realizada pelo caminho mais curto, mas quando se tivesse que instaurar desvios ou adiar a satisfação em função das 
condições do mundo externo. Apesar de o princípio de realidade contradizer o princípio de prazer, o acúmulo de energia se daria para que o aparelho fosse mais bem servido, isto é, para que se realizasse uma ação específica e, com isso, melhor se utilizasse o princípio de prazer.

Freud (ibidem) salientou que o objeto que se apresenta na tela da percepção e que possibilita a queda do estado de tensão; seja ele o seio materno ou qualquer outro objeto que aplaque o incômodo, deixa como resultado uma inscrição mnêmica, uma lembrança desse objeto na memória do bebê. Guarda-se no aparelho psíquico tanto os traços de objetos vinculados a experiências de prazer quanto os associados a experiências de desprazer. O que se configura no primeiro caso é que, quando há um novo aumento de tensão e um consequente estado de insatisfação, o recém-nascido anseia retornar àquele estado anterior que o satisfez. Mas como o objeto não está presente a todo o momento, há um investimento em sua imagem mnêmica, isto é, há uma alucinação do primeiro objeto com o intuito de voltar ao estado de prazer. Já no segundo caso, procura-se usar os objetos registrados para evitar experiências de desprazer semelhantes às primeiras já vivenciadas.

Lacan (1959-1960/1991) salienta que a dinâmica do aparelho neurônico analisado por Freud é uma "topologia da subjetividade que é edificada e construída na superfície de um organismo” (p.55). Ele nos fala que toda a teoria freudiana da memória se alicerça naquilo que Freud definiu como "inscrições", não apenas como o que é da ordem da impressão, mas "no sentido de algo que constitui signo e que é da ordem da escrita" (p.55). Diante daquilo que foi inscrito como marca mnêmica, sobrevém um complexo de memória que passa a fornecer um trilhamento (Bahnung), um caminho específico que funda a orientação e as escolhas do sujeito. Essas Bahnungs, que Lacan (1959-1960/1991) não mais analisa como facilitações neurônicas, mas como uma organização que se forma de representação (Vorstellung) em representação, são governadas pelo princípio de prazer e almejam descarregar a excitação no aparelho, evitando que o psiquismo fique com uma alta carga de energia.

\section{O TRAUMA E A DEFESA COMO MODOS DE INSERÇÃO DO SUJEITO NA NEUROSE}

Os textos freudianos do final do século XIX nortearam-se por uma concepção econômica e sustentaram uma tese muito bem definida de que o aparelho psíquico se movimentaria na direção do rebaixamento das tensões provenientes de estímulos internos e externos. No entanto, a partir do discurso de seus pacientes, Freud foi percebendo que existiam excitações que eram aflitivas para o sujeito e que este era incapaz de dominá-las ou de elaborá-las psiquicamente, colocando 
em xeque o próprio princípio de constância, que atesta que o psiquismo deve manter o quantum de excitação no nível mais baixo possível.

A partir dessas constatações, foi-se configurando a ideia de que quando não houvesse nenhuma reação frente a alguma experiência que causasse um aumento de excitação, a lembrança do evento preservaria a carga afetiva em questão, fazendo com que o afeto original permanecesse vívido e atuante no psiquismo. Era a não ocorrência de uma ab-reação adequada que faria com que a lembrança dessas experiências se tornasse patogênica.

Freud (1893a/1996) concluiu que esses eventos sobre os quais o sujeito não conseguia ab-reagir à carga afetiva consistiam em traumas psíquicos (p.45) e estavam intimamente relacionados com a emergência dos sintomas subsequentes. Além de o trauma estar vinculado à impossibilidade de eliminar a carga de afeto, seja por uma reação motora, seja por uma atividade associativa de pensamento, os outros fatores que contribuíam para que esses acontecimentos recebessem essa denominação seriam o fato de eles evocarem um afeto de susto (p.41), isto é, um afeto penoso que poderia proporcionar susto, dor física, vergonha ou angústia, e ter uma relação com alguma parte do corpo da pessoa que vivenciou o evento.

Freud começou a se aproximar das ideias sobre o trauma a partir das formulações de Charcot sobre a histeria. Como se empregava a racionalidade para explicar os fenômenos humanos e da natureza, as manifestações histéricas passaram a embaraçar a razão médica da época. Os cientistas dos séculos XVIII e XIX, pautados pelo privilégio que se dava à razão como fonte de conhecimento, acusavam que a histeria se tratava de simulação, de má-fé, aludindo a uma estranha falta de conformidade à regra.

Mas Charcot sustentou a hipótese de ser uma causação não orgânica o motivo do surgimento dos fenômenos histéricos. Na tentativa de entender a etiologia da histeria, Charcot buscou simular experiências traumáticas e propiciar o advento de fenômenos somáticos utilizando o mecanismo da sugestão hipnótica. Ao confirmar a emergência de algumas dessas manifestações após a sugestão, o autor concluiu que os sintomas histéricos estavam relacionados a algum acontecimento traumático na vida do paciente, denominando histeria traumática o conjunto desses fenômenos.

Freud seguiu os caminhos de Charcot quanto à hipótese de uma causalidade não orgânica para as manifestações histéricas. Em um de seus primeiros artigos publicados sobre o caso — Histeria $(1888 / 1996)$ — - Freud percebeu que não foi achada nenhuma alteração neurológica na histeria. Para ratificar sua argumentação, observou que seus pacientes histéricos tomavam os órgãos pelo sentido comum, desrespeitando, em seus sintomas, regras anatômicas fundamentais para caracterizar uma causação neurológica. Ele forneceu uma série de exemplos que lhe permitiram afirmar que a paralisia histérica consistia em uma paralisia 
em representação (FREUD, 1893 [1888-1893]/1996, p.204), e que a lesão, em vez de orgânica, seria funcional. Haveria uma modificação na funcionalidade de um órgão devido à impossibilidade de a representação desse órgão estar acessível às representações conscientes, o que sugeria que o órgão representado teria uma estreita relação com a lembrança do trauma.

A obsessão foi se aproximando da histeria quanto à sua etiologia. Ambas eram caracterizadas por um excesso de sexualidade na infância e pela posterior instauração de um mecanismo de defesa contra essa mesma sexualidade (FREUD, 1896a/1996). Nos dois casos, o eu buscava retirar a carga de afeto da representação incompatível, enfraquecendo-a. Mas a localidade para onde houvesse o deslocamento do afeto aflitivo seria um dos fatores que permitiram a Freud distinguir as classes de neurose: a histeria, que deslocava o afeto para uma localidade somática, isto é, convertia-o para uma parte do corpo, e a obsessão, que o irradiava para a cadeia representativa, transformando as representações substitutas em representações obsessivas (1894/1996). Tanto as representações obsessivas quanto as localidades do corpo para onde havia a conversão se configuravam como formações substitutivas das representações traumáticas, isto é, como a "melhor” formação de compromisso entre, de um lado, a demanda de satisfazer o princípio de constância com as descargas de excitação, e, de outro, a preservação do eu das representações que foram banidas da consciência.

A partir daí, foi chegando à conclusão de que a localidade aonde se instaurava a conversão seria um lugar vinculado à experiência do trauma. Mas dois fatores foram considerados determinantes para que o sujeito respondesse ao trauma de uma forma e não de outra: a época em que o trauma sexual teria ocorrido e a natureza desta experiência traumática.

Freud (1896a/1996) acreditava que a forma como o sujeito respondia à experiência primeira e como ele construiria as suas manifestações sintomáticas poderiam ser respondidas pela idade da criança durante o evento sexual. Acreditava-se que para o sujeito se estruturar como histérico, as cenas sexuais deveriam advir no primeiro período da infância (até os quatro anos); já para a constituição obsessiva, ocorreria entre os quatro e os oito anos. Essa tentativa de explicação relacionava-se ao fato de a histeria se instituir quando a criança ainda não dispusesse de palavras para traduzir a experiência traumática em imagens verbais, restando-lhe apenas a conversão somática. Seria apenas em um período posterior aos quatro anos, quando a criança começasse a manipular a palavra, que haveria a possibilidade de a tradução incidir na esfera psíquica.

Já em relação à natureza do trauma, acreditava-se que a experiência primária do histérico com o outro teria sido desprazerosa, uma sedução súbita, enquanto a experiência sexual do obsessivo seria acompanhada de um “a mais” de prazer (FREUD, 1896/1996). Ambos se caracterizavam como uma vivência de passi- 
vidade sexual, em que a criança estava sujeita às ações do outro. Entretanto, na neurose obsessiva, sobreviria uma atividade sexual que foi relacionada ao prazer adquirido na experiência. É nesse sentido que Lacan (1973-1974/s.d.) fez um jogo de justaposição das palavras traumatisme, trop (demasiado) e trou (buraco) para falar que o trauma do obsessivo alude a um tropmatisme (um trauma que traz um excesso de prazer), enquanto o do histérico faz referência a um troumatisme (um trauma que faz buraco no sistema representativo por ser vivenciado como uma experiência desprazerosa).

Além disso, duas conclusões foram tiradas a partir da análise do caráter do trauma infantil. A primeira se refere ao fato de a obsessão ser derivada da histeria, isto é, ter um substrato histérico, que seria a passividade sexual antes da ação prazerosa, visto que o sujeito, antes de tudo, é seduzido. A segunda diz respeito a uma característica sintomática presente nas obsessões, que são as autoacusações. Pelo fato de o obsessivo ter obtido na infância uma parcela de gozo naquilo que Freud denominou "atos de agressão sexual” (1896/1996, p.169), que nada mais são que a experiência sexual infantil, recriminações dirigidas à própria pessoa sobreviriam posteriormente. Essas autorrecriminações se vinculariam à representação dessas experiências e emergiriam na consciência de maneira deslocada como representações obsessivas. Sobre essas representações, Freud (1896b/1996) concluiu que "quando seu significado íntimo é reconhecido pela análise, nada passa de recriminações dirigidas pelo sujeito a si mesmo por causa desse gozo sexual antecipado" (p.154).

Freud não se satisfez em apenas determinar o trauma como um evento que não teria sua carga de afeto eliminada — também o qualificou como uma experiência de ordem sexual: o trauma seria decorrente de um evento sexual infantil que despertasse um afeto aflitivo por ser de difícil elaboração. Esse evento, qualificado como uma sedução traumática, ${ }^{1}$ ocorreria antes da maturidade sexual e na relação com um adulto.

Não podemos perder de vista que a condição de desamparo infantil faz com que a criança seja dependente dos outros à sua volta, o que faz com que os cuidados corporais dispensados ao lactente possam ser interpretados postumamente por uma perspectiva sexual. Desse modo, conforme argumenta Farias (1993), a sedução pode se caracterizar não só como uma experiência sexual propriamente dita, como também por uma cena, um acontecimento, um gesto ou uma palavra que se associará a essa conotação.

\footnotetext{
${ }^{1}$ A teoria da sedução, apresentada entre os anos de 1895 e 1897, foi postumamente reformulada quando Freud detectou a importância do papel das fantasias para que uma ideia fosse referida como traumática.
} 
Apesar de Freud discorrer sobre quais seriam as vicissitudes dessa primeira experiência para que ela fosse qualificada como traumática, argumentou, em Observações adicionais sobre as neuropsicoses de defesa (1896/1996), que um evento só seria considerado um trauma psíquico quando fosse articulado a uma segunda experiência. Por considerar a inexistência da sexualidade na criança, o autor admitiu que seria somente após o advento da puberdade que um segundo evento poderia, de maneira associativa e retroativamente, fornecer uma significação sexual para a cena infantil. Isso permite concluir que todas as circunstâncias decorrentes do trauma, como o aumento de tensão no psiquismo e os mecanismos de defesa subsequentes, não ocorreriam no momento da experiência, mas quando ela passasse a receber uma conotação sexual, fazendo figurar uma lembrança que produziria desprazer. Logo, os fatores que qualificavam como traumática a situação primeira só seriam relevantes em um momento posterior.

Essa construção teórica sobre um segundo tempo na dinâmica do trauma antecipou, mesmo que nas entrelinhas, desenvolvimentos teóricos subsequentes. O que passou a se tornar relevante foi que o fator traumático não seria uma realidade factual - embora o autor ainda acreditasse nisso e tivesse se debruçado detidamente nos fatos reais vivenciados pela criança-, mas sim uma lembrança, um traço mnêmico, indicando que é na realidade psíquica que um evento se torna traumático.

Freud procurou os meios suficientes para uma determinação diagnóstica e fez da sua clínica uma pergunta sobre a causa. Ele chegou à tenra infância e concluiu que havia um material factual de experiências sexuais vividas no próprio corpo que resistiam à recordação devido à moralidade e à vergonha, mas que retornariam sobredeterminados constituindo os sintomas. Ele se aproximou da concepção sobre a existência de conteúdos traumáticos ao procurar os elementos vivenciados pelas histéricas que poderiam ser a causa dos seus sintomas. No entanto, ele reconheceu que o traumatismo era efeito de uma alucinação que só se instituiria em um segundo momento, deslocando o foco da experiência factual para uma ilusão. Tal formulação teórica teve seu pleno sentido quando Freud conclui que "os histéricos sofrem de reminiscências" (1894/1996, p.217), isto é, de marcas mnêmicas. Essa conclusão, juntamente com a posterior descoberta das noções de fantasia, de realidade psíquica e de sexualidade infantil, permitiu evocar o posterior reordenamento da teoria do trauma.

\section{PULSÃO E FANTASIA: UMA REORGANIZAÇÃO DA TEORIA TRAUMÁTICA}

Embora tenha sido somente em 1905 que o autor tenha abdicado da teoria sobre a sedução traumática, nos anos anteriores ele já expressava declaradamente suas dúvidas sobre essa teoria. Em A etiologia da histeria (1896c/1996), por exemplo, ao 
tentar elucidar o trauma da sedução, Freud se deparou com pontos que evidenciavam uma sexualidade precoce na histeria, o que contrariava a ideia de uma inocência sexual da criança. Um ano depois, na carta enviada a Fliess (Carta 69), ele demonstrou seu ceticismo sobre o material relatado pelos seus pacientes, chegando a supor que não havia indicadores de realidade no inconsciente, o que impossibilitava distinguir o material real do fantasístico. Todos esses fatores foram repercutindo na forma de teorização freudiana que tinha como tema o trauma psíquico, fazendo com que Freud afirmasse, já nessa época, que não acreditava mais em sua neurótica (1897/1996, p.309). Mas o distanciamento dos primeiros pressupostos não se deu de uma maneira linear e coerente, uma vez que Freud ainda continuou a buscar os dados de realidade que descrevessem o evento primeiro.

A importância dada à fantasia foi se tornando presente de maneira singela, desde o período dos Estudos sobre a histeria (1893-1895), quando ela era associada aos estados de ausência de consciência (estados hipnoides), passando pela Interpretação dos sonhos (1900/1996), em que a fantasia era análoga à formação e à estrutura dos sonhos, até tomar seu pleno valor no segundo dos Três ensaios sobre a teoria da sexualidade, publicado em 1905, com a descoberta das vivências sexuais infantis, como as atividades autoeróticas, a masturbação, as teorias sexuais da infância, dentre outras.

A sedução passou a não se tornar prerrogativa para instaurar a vida sexual, uma vez que esta também poderia decorrer de fatores internos e constitucionais. Diante do exemplo do chuchar, Freud (1905/1996) obteve argumentos para afirmar que a atividade sexual advém ancorada em funções internas que servem à preservação da vida. Isso é evidenciado quando o bebê, após a mamada, busca prolongar a satisfação chupando o dedo, isto é, satisfazendo-se através de uma atividade autoerótica e elegendo a boca como uma zona erógena, como uma localidade que se torna meio para a obtenção de satisfação sexual.

Ao se admitir a sexualidade infantil, reconheceu-se também a incidência da atividade pulsional. A teoria da pulsão veio reorganizar a ideia neurológica anterior sobre a incidência de estímulos internos no corpo. Apesar de também ser qualificada como uma exigência de trabalho imposta ao psíquico, sua definição ultrapassou o fator motor que ela representa. Ela foi qualificada como um excesso de energia dispersa que advém de maneira constante, mas que só é evacuada quando conectada às zonas erógenas do corpo. Assim, é em torno dessas localidades que a pulsão se fixa, o que faz com que a sua força impelente parta dessas regiões em busca de satisfação. A partir daí, passam a subsistir regiões privilegiadas que proporcionarão uma satisfação parcial e limitada a essas localidades. 
A pulsão caminha rumo à descarga, e para que haja descarga deve haver, antes de tudo, excitação. Para Freud (1905/1996), a fonte da pulsão é um processo excitatório em um órgão que tem como alvo a eliminação desse estímulo. Em relação a isso, Lacan (1964/2008) afirmou que a excitação da pulsão difere de qualquer excitação que provenha do mundo externo ou que se dê no nível da necessidade (fome, sede, etc.). Ela advém de regiões superficiais do corpo que são investidas pela própria pulsão. Segundo o autor, a necessidade (Not) difere da exigência pulsional (Bedurfnis), uma vez que não é pelo alimento (Not) que a boca se satisfaz, mas sim pelo prazer de boca, "o que vai à boca, retorna à boca, e se esgota nesse prazer" (p.165).

É somente no contato com um terceiro, geralmente a mãe, que há a possibilidade de se introduzir no corpo zonas de investimento pulsional. Devido ao estado de inacabamento anatômico do recém-nascido e de sua consequente dependência de um terceiro, há a incidência de uma série de demandas simbólicas em algumas regiões do corpo, como a boca, o ânus, dentre outras, que se remetem aos primeiros cuidados da mãe para com o bebê. E pela importância que o discurso do Outro fornece a essas localidades, elas se tornam regiões de troca de mensagem simbólica, sendo a partir daí que o infante poderá responder e se colocar.

Nessa dinâmica, a atividade sexual sobrevém ancorada nessas localidades que servem à preservação da vida. Conforme foi afirmado anteriormente, a criança investe nas localidades que aplacaram os primeiros incômodos e que foram meio das primeiras satisfações com o objetivo de reviver os primeiros estados de prazer, resultando em que essas bordas se tornem regiões libidinizadas às quais a pulsão irá se aderir e demandar satisfação sexual.

O corpo orgânico é, portanto, uma superfície propícia à escrita, tornando-se sede das primeiras marcas e dos primeiros investimentos pulsionais. A incidência da linguagem subverte o corpo orgânico em um corpo simbólico, um corpo que, ao se comunicar com o Outro, perde objetos nessa relação (o seio, as fezes, o olhar da mãe que se desvia da criança, dentre outros), fazendo dos orifícios comunicativos zonas erógenas que buscarão reencontrar tais objetos para obter uma satisfação perdida.

Ao se deparar com a sexualidade infantil e considerar a atividade pulsional como primária, Freud (1905/1996) admitiu que a teoria da sedução não respondia às circunstâncias da pulsão sexual na infância. Nesse momento, o trauma da sedução foi deslocado para o trauma gerado pela pulsão. Lacan (1964/2008) veio falar do sujeito acéfalo da pulsão para se remeter a essa vertente que a princípio é desconectada de uma determinação simbólica e que clama por satisfação. Passou a haver então uma relação entre a tensão gerada pela pulsão e a sua captação pelo sistema simbólico, sugerindo que quanto menos desenvolvida fosse a 
aparelhagem simbólica menor seria a capacidade para se defender da incidência da pulsão, e consequentemente, mais marcante seria o trauma. Assim, para dar conta desse momento originário, sobreviria uma estrutura fantasística, edificada pelo próprio sujeito, que interpretaria a atividade pulsional e, consequentemente, determinaria uma maneira particular para lidar com ela, resultando em um caminho simbólico específico trilhado por ele próprio. Essa nova conceituação isolou a teoria anterior, que buscava atingir o real da cena, e deslocou a perspectiva do trauma, que até então era pensado como contingente e patológico, para constitutivo e universal.

O trauma da pulsão só poderia ser captado a posteriori por um aparato simbólico. Freud inseriu denominações para se referir a essa primeira tentativa de lide para com o traumático, como, por exemplo, o recalque originário, que alude à primeira operação do recalque diante do traumatismo, dando origem às primeiras formações inconscientes; e as fantasias originárias, que expressam as primeiras tentativas de representação para aquilo que se coloca como um enigma. Os dois termos estão relacionados e remetem ao momento inaugural de aquisição da função simbólica.

Esse primeiro momento de simbolização, chamado na teoria lacaniana de fantasia fundamental, circunscreve um ponto de partida para um encadeamento significante. A formação simbólica se estrutura em uma série de significantes que em si nada significam. Seria somente pelo advento de um significante dois $(\boldsymbol{\vee})$ que interprete o primeiro $(\boldsymbol{\vee})$ e que forneça retroativamente um saber a ele que haveria a possibilidade de engendrar-se uma significação. Esse mecanismo de retroação é notável em diferentes momentos da obra freudiana, como na própria teoria da sedução, quando o autor já declarava que não seria mais a questão da origem o fator determinante, mas sim o papel arrogado a um segundo momento. Por ser de reminiscências que o sujeito sofre, Freud deixou entender que o fantasma media a experiência traumática. E o que se tornou relevante com a descoberta da sexualidade infantil foi que atribuir uma conotação traumática a uma cena infantil seria um modo simbólico de lidar com a força da pulsão. Assim, a cena de sedução que Freud visava desvendar passou a ser um efeito da fantasia, apresentando-se ao sujeito como um recurso para solucionar os enigmas de sua fundação.

A dinâmica da relação entre um momento inaugural, ausente de simbolização, e o ingresso do sujeito na ordem simbólica foi expressa por Freud também em seu texto posterior Totem e tabu (1913 [1912-1913]/1996). Ele utilizou o mito como um recurso para interpretar um momento excluído da estrutura. Esse mito se organizaria pelo assassinato de um elemento primeiro (o pai primevo) que teria acesso a um gozo absoluto. Com a ausência do pai real, sua lei seria presentificada simbolicamente por seus filhos, permitindo formar um conjunto 
regido pela mesma lei, pela lei do pai. O fator importante expresso nesse mito é que, para o pai advir como uma instância simbólica, ele deve ser excluído do conjunto, isto é, deve haver uma anterioridade lógica, impossível de ser simbolizada, que se constitui como função estruturante. Lacan, no seminário Mais, ainda (1972-1973/2008), evocou essa dinâmica na primeira fórmula daquilo que ficou conhecido como as "fórmulas quânticas da sexuação". Ao interpretá-la, compreende-se que existe um "x” (o pai da horda) para o qual não incidiu nenhuma lei simbólica; logo, ele tem acesso a um gozo universal por não estar sujeitado à lei da linguagem. Em contrapartida, ele é prerrogativa para que todo " $x$ " que se insira no conjunto seja castrado, seja subordinado à linguagem, e consequentemente, que seja apenas por meio dela que se possa falar desse momento primeiro.

O que é mencionado no exemplo de Freud e na fórmula lacaniana é a articulação entre a pulsão e a fantasia. O gozo absoluto remete a um momento primeiro, mítico, de uma exigência pulsional dispersa, que é traumática e que só pode ser abarcada de maneira parcial a partir da construção de uma tessitura fantasmática. É através dessa formação simbólica que o sujeito busca lidar com o real da pulsão, colocando em ação o recalque originário e fundando um saber inconsciente. O inconsciente se edifica como um saber concernente à verdade da pulsão, ele nasce como tentativa de circunscrição de uma verdade que, simbolicamente, sempre será semidita, nunca toda. A verdade da pulsão alude a um real de gozo que se impõe como um limite que o aparato psíquico possa tolerar.

Diante disso, podemos supor que a relação da pulsão com a fantasia é análoga àquele primeiro momento em que Freud visava atingir a cena da sedução, ou seja, foi por uma fantasia de sedução que Freud chegou à descoberta dos ímpetos pulsionais na infância, denotando, tal como as fantasias, uma primeira tentativa simbólica para dar conta desse excesso pulsional que aflige o sujeito.

\section{TRAUMA, DAS DING E A ESCOLHA DA NEUROSE}

Freud (1950 [1895]/1996) partiu das primeiras experiências do recém-nascido com o outro, denominadas Nebenmensch (Complexo do próximo), para explicar como o sujeito apreenderia a realidade. Segundo ele, tal apreensão seria decomposta em duas partes: de um lado, situaria tudo o que é qualificado como os atributos do objeto, como as “Vorstellungen primitivas” (LACAN, 1959-1960/1991, p.67), que podem ser apreendidas pela memória; e, de outro, um elemento que resiste a qualquer tentativa de inserção no simbólico, e que por isso sempre se revela estranho. É o que Freud denominou das Ding, a Coisa, e que Lacan definiu como "o verdadeiro segredo" (idem, p.60). Das Ding foi caracterizado como um 
campo foracluído do espaço das representações, aludindo a um cavo estrutural, a um furo no simbólico que movimentaria toda a dinâmica subjetiva.

Ao analisarmos o âmbito instintivo, percebemos que o comportamento animal, seja ele sexual, de proteção, de alimentação, etc. é padronizado, ou seja, segue um script, um saber impresso no corpo que indica, por exemplo, a época da reprodução, com qual animal irá procriar, o que sugere uma circularidade fechada para a manifestação desses comportamentos. Nesse caso, a falta funciona de maneira sígnica, pois, como afirma Wine, uma "falta-necessidade opera como um significante que tem como significado um objeto apropriado para preencher satisfatoriamente essa falta” (1992, p.30). Mas no campo do humano há uma modificação nessa forma de funcionamento, uma vez que há um cavo nesse script, um buraco nesse saber instintual. Esse furo real alude a um ponto sem significação, que é inapreensível e que não pode ser tamponado por nenhum objeto.

Diante da incidência desse cavo na estrutura, isto é, de das Ding, Lacan nos mostrou que há um outro campo que transcende a lógica instintiva e do comportamento pautado na imagem. Esse é o campo simbólico, o lugar do endereçamento e da constituição do sujeito, o lugar para o qual o sujeito endereça a falta real que atravessa o campo do humano. Diante disso, podemos dizer que ao mesmo tempo que das Ding se apresenta como aquilo que pôde separar-se de tudo o que o sujeito começou a nomear, a Coisa também organiza a estruturação simbólica do psiquismo.

Aferimos anteriormente que seria o real da pulsão que organizaria a cadeia representativa, mas o que se configura ao analisarmos a conceituação de das Ding é que a Coisa é correlativa a uma vertente da pulsão, isto é, ao objeto através do qual a pulsão almeja se satisfazer. Das Ding alude ao objeto nunca tido e impossível de alcançar; em contrapartida, ela também se remete ao verdadeiro objeto visado pela pulsão, o único que lhe proporcionaria a satisfação plena rumo à ausência de excitação.

Mas pela Coisa transcender o registro simbólico e, portanto, ser impossível de atingi-la, o que fornecemos à pulsão, como afere Coutinho Jorge, são sempre "substitutos dessa Coisa, através dos quais ela vai se satisfazendo parcialmente, sempre insistindo em pedir mais" (2010, p.137). Os objetos substitutos que oferecemos à demanda pulsional remetem aos primeiros objetos perdidos na experiência com o Outro (voz, seio, olhar, dentre outros), permitindo parcializar a pulsão e constituir zonas erógenas específicas. Mas nenhum objeto, mesmo os que estão vinculados a essas regiões, fornecerão satisfação total à pulsão. O que apenas podemos aferir é que a sua força impelente parte dessas regiões, contorna os objetos que se perderam na relação com o Outro (e que supostamente trariam a satisfação plena), e retorna à mesma zona erógena. Assim, todos os objetos que entram nessa série mantêm a sua matriz, ou seja, são objetos destacáveis, 
cedíveis, situados entre a criança e o Outro, e que retomam a sua dimensão de perda, fazendo alusão a das Ding.

A teorização freudiana sobre a apreensão da realidade faz com que examinemos a questão da origem, isto é, o objeto real que foi perdido, que foi fonte de satisfação e que instaurou a busca do reencontro. Vimos que a primeira experiência da realidade institui o estranho (das Ding) e a cadeia representativa de maneira simultânea, pois a Coisa só é estranha em uma e para uma rede de representações — ela não se situa como objeto perdido em uma anterioridade cronológica em relação às Vorstellungen. Dessa forma, podemos dizer que o objeto só foi perdido porque o significante forneceu retroativamente essa significação, e não porque houve um objeto primeiro. É apenas pela impossibilidade de qualquer objeto encontrado trazer a satisfação plena que se acredita que houve um primeiro objeto que tenha sido fonte desse tipo de satisfação.

A organização representativa a caminho do objeto segue um direcionamento governado pelo princípio de prazer, mas o campo que permite instaurar esse trilhamento está situado para além desse próprio princípio. Lacan (1959-1960/1991) associa esse campo, isto é, o das Ding freudiano, ao Outro absoluto — não ao outro semelhante que supomos compreender e que nos orienta de Vorstellung em Vorstellung - , o Outro caprichoso, arbitrário, em que não se pode ter garantia e segurança de nada que dele provenha, ou seja, um Outro ao qual a linguagem não fornece elemento algum para compreender o que ele quer. De acordo com Julien (1996), nesse campo o sujeito se depara com o enigma do gozo do Outro, com o campo que, freudianamente falando, remete ao para além do princípio de prazer. É o que Lacan (1959-1960/1991) vem nos dizer ao afirmar que "para além de um certo limite de nosso prazer, estamos numa posição inteiramente enigmática" (p.119).

A compulsão à repetição rumo à satisfação perdida então independe do saber do Outro, fazendo com que haja uma dimensão pré-simbólica, não apreensível pela linguagem, e que por isso não é passível de significação. O plano do gozo faz menção à Coisa, a das Ding, tornando o campo do Outro perfurado e incompleto. O único significante que poderia fazer menção à inconsistência da ordem simbólica quando ela é atravessada por uma incursão de gozo seria o significante da falta no Outro — S(\%). Žižek (1992) nos fala que seria como proteção à incidência dessa falta no registro simbólico — S $(\%)$ - que a fantasia adviria, provindo como possibilidade de constituir uma significação absoluta — $\mathrm{s}(\mathrm{A})$.

A busca desse primeiro objeto, desse Ding enigmático, obriga o sujeito a estabelecer inconscientemente um movimento repetitivo de reencontro, instaurando um percurso singular. E Lacan (1959-1960/1991) retoma a formulação freudiana sobre a natureza da experiência primeira para pontuar que é em uma relação com o próximo e, consequentemente, com esse objeto excluído da estrutura, 
que se evidenciam os diversos tipos de manifestações neuróticas. "É em relação a esse das Ding original que é feita a primeira orientação, o primeiro assento da orientação subjetiva que chamaremos de Neurosenwahl, a escolha da neurose. Essa primeira moagem regulará doravante toda a função do princípio do prazer” (LACAN, 1959-1960/1991, p.70).

Com a releitura lacaniana, o Ding se torna o suporte de uma aversão para a histérica e de um prazer em demasia para o obsessivo, prescrevendo um direcionamento desejante particular à busca do objeto para cada uma das classes de neurose. É ainda o Ding freudiano que se constitui como um elemento mítico, pré-simbólico e anterior a todo recalque pela perspectiva do a posteriori. As formações do inconsciente e as estruturas neuróticas são assim interpretadas tanto pelo enfoque do desejo quanto pelo da defesa. O primeiro acena para uma formação inconsciente que segue a lógica do princípio de prazer em busca do objeto primeiro (das Ding), enquanto o segundo considera a formação simbólica inconsciente como tentativa de defesa para lidar com a persistência da pulsão em busca de das Ding.

Diante disso, podemos aferir que o trauma é aí evidenciado como tudo aquilo que pôde separar-se de uma nomeação e de uma articulação significante, mas que ao mesmo tempo é condição para que a Lei da linguagem advenha. O não sentido concernente ao trauma é o âmago daquilo que faz estrutura para todas as neuroses. É apenas por meio de uma resposta a essa anterioridade lógica que se permite diferenciar as classes de estrutura, postulando modos de queixas específicas e caminhos desejantes particulares para com isso de que o simbólico constantemente não dá conta.

Recebido em 20/7/2012. Aprovado em 7/10/2012.

\section{REFERÊNCIAS}

COUTINHO JORGE, M. A. (2010) Fundamentos da psicanálise de Freud a Lacan: a clínica da fantasia, v.II. Rio de Janeiro: Jorge Zahar.

FARIAS, F. R. (1993). Histeria e psicanálise: o discurso histérico e o desejo de Freud. Rio de Janeiro: Revinter.

FREUD, S. (1996) Edição standard brasileira das obras psicológicas completas de Sigmund Freud. Rio de Janeiro: Imago.

(1888) “Histeria” v.I, p.75-96.

(1893 [1888-1893]) "Algumas considerações para um estudo comparativo das paralisias motoras orgânicas e histéricas”, v.I, p.199-216. (1893a) "Sobre o mecanismo psíquico dos fenômenos histéricos: comunicação preliminar”, v.II, p.39-53. 
(1894) “As neuropsicoses de defesa”, v.III, p.51-72.

(1950 [1895]) "Projeto para uma psicologia científica”, v.I, p.335-454. (1896) "Observações adicionais sobre as neuropsicoses de defesa", v.III, p.159-183.

(1896a) “Carta 46”, v.I, p.276-280.

(1896b) “A hereditariedade e a etiologia das neuroses”, v.III, p.141155.

(1896c) “A etiologia da histeria”, v.III, p.187-215.

(1897) “Carta 69”, v.I, p.309-311.

(1900) “A interpretação dos sonhos”, v.IV e V, p.11-700.

(1905) “Três ensaios sobre a teoria da sexualidade”, v.VII, p.119-231. (1913 [1912-1913]) “Totem e tabu”, v.XIII, p.13-163.

(1920) "Além do princípio de prazer”, v.XVIII, p.13-75.

JULIEN, P. (1996) O estranho gozo do próximo: ética e psicanálise. Rio de Janeiro: Jorge Zahar.

LACAN, J. (1954-1955/1985) O Seminário, livro 2: O eu na teoria de Freud e na técnica da psicanálise. Rio de Janeiro: Jorge Zahar. (1957-1958/1999) O Seminário, livro 5: As formações do inconsciente. Rio de Janeiro: Jorge Zahar. . (1959-1960/1991) O Seminário, livro 7: A ética da psicanálise. Rio de Janeiro: Jorge Zahar. (1964/2008) O Seminário, livro 11: Os quatro conceitos fundamentais da psicanálise. Rio de Janeiro: Jorge Zahar. (1972-1973/2008) O Seminário, livro 20: Mais, ainda. Rio de Janeiro: Jorge Zahar.

. (1973-1974/s.d.) Seminário 21: Le non-dupes errent. Versión completa de la Escuela Freudiana de Buenos Aires.

WINE, N. (1992) Pulsão e inconsciente: a sublimação e o advento do sujeito. Rio de Janeiro: Jorge Zahar.

ŽIŽEK, S. (1992) Eles não sabem o que fazem: o sublime objeto da ideologia. Rio de Janeiro: Jorge Zahar.

Renato Jesus A. de Praga Palma

renatoppalma@hotmail.com

Ana Maria M. da Costa

ammcosta@terra.com.br 
